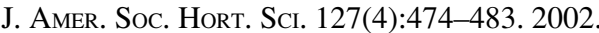

\section{Molecular Approaches to Altered C Partitioning: Genes for Sucrose Metabolism}

\author{
Karen E. Koch ${ }^{1}$ and Ying Zeng \\ Horticultural Sciences Department, University of Florida, Gainesville, FL 32611
}

\begin{abstract}
AdDitional InDEX wORDs. fruit set, hexokinase, invertase, maize, ovule, potato, sucrose synthase, sugar sensing, sugar signal transduction, tobacco, tomato
\end{abstract}

Sucrose metabolism can affect whole-plant $\mathrm{C}$ partitioning in at least two major ways: the first is by providing substrates for growth at different sucrose-importing sites (sinks), and the second is by generating signals to sugar-responsive genes. Sucrose and its metabolism have long been known to play a central role in the allocation of $\mathrm{C}$ resources among plant parts. It is the primary transport sugar in the phloem of most species (Zimmerman and Ziegler, 1975), where it supports the C demands of virtually all nonphotosynthetic cells in these plants. Sucrose and its use are thus essential for growth of most fruit, flowers, stems, new leaves, roots, and meristems. Extensive evidence has shown that this growth and the capacity for organs to compete for sucrose, are often closely related to activity of enzymes for sucrose metabolism (Geiger et al., 1996; Quick and Schaffer, 1996).

A second aspect of sucrose metabolism central to manipulations of $\mathrm{C}$ partitioning is its role in signals for altered gene expression. Some genes are especially sensitive to sugar availability, and these include genes that can alter development (Koch, 1996; Jang et al., 1997; Riou-Khamlichi et al., 2000; Smeekens and Rook, 1997). Depending on the gene involved, sugars can upregulate their expression, down-regulate their expression, or have relatively limited effect (Koch, 1996; Koch et al., 2000). The type of sugar is also important to initiation of sugar signals, so that the effect of imported sucrose on gene expression can vary markedly with the extent of its metabolism, the path of this metabolism, and the precise site where it occurs (Koch, 1996; Koch et al., 1996, 2000; Lalonde et al., 1999). Thus, in a general sense, sucrose can be viewed as a long-distance signal conveying information on plant carbohydrate status (Koch, 1996; Jang et al., 1997; Smeekens and Rook, 1997). However, in a more specific sense, its ultimate effect on gene expression in an importing organ will depend on the physical and metabolic path followed by sucrose entering a given tissue (Chiou and Bush, 1998; Gibson, 2000; Koch, 1996; Koch et al., 1996, 2000; Lalonde et al., 1999; Smeekens and Rook, 1997; Weber and Wobus, 1997).

\section{Two paths of sucrose cleavage}

Products and Potential Sugar signals DifFer. Invertase and the reversible sucrose synthase reactions are the only known enzymatic paths for sucrose cleavage in vascular plants. They differ in several important ways, but differences in products of the reactions are especially significant. Figure 1 shows that invertase hydrolyzes sucrose (12-C disaccharide) directly to its glucose and fructose constituents (6-C hexoses). The reaction is essentially irreversible and its products differ from those of the degradative reaction of sucrose synthase. Although free fructose is produced during both reactions, free glucose results only from invertase activity, and

Received for publication18 Dec. 2002. Accepted for publication 16 Apr. 2002. Florida Agricultural Experiment Station journal series R-08829.

${ }^{1}$ To whom correspondence should be addressed; e-mail kek@gnv.ifas.ufl.edu.
UDP-glucose is formed during sucrose synthase action.

The difference in reaction products is important to the potential roles of invertases and sucrose synthases in $\mathrm{C}$ partitioning. First, the hexose products of the invertase reaction (glucose and fructose) each require one additional ATP for subsequent entry into glycolysis, an energy requirement that could be critical under conditions such as low oxygen stress (Koch et al. 2000; Perata et al., 1997; Zeng et al., 1998, 1999). Second, glucose is favored as a major osmotic constituent in vacuoles during cell expansion (Avigad, 1982; Morris and Arthur, 1984; Walker and Pollock, 1993), whereas UDP-glucose can contribute more directly to biosynthesis of complex polysaccharides [e.g., starch (Quick and Schaffer, 1996), or cellulose (Delmer and Amor, 1995; Nolte et al., 1995)].

Especially important, however, is the influence of hexoses on expression of sugar-modulated genes. Although some genes respond to sucrose per se (Barker et al., 2000; Chiou and Bush, 1998; Loreti et al., 2000; Rook et al., 1998; Smeekens, 2000), most examined thus far respond to hexose products of sucrose cleavage via one of at least three mechanisms (see section on signals). In contrast, UDP-glucose produced during the sucrose synthase reaction does not appear to be sensed directly by currently known mechanisms for sugar signaling (Koch, 1996; Smeekens, 2000). The UDP-glucose may be sensed by alternate means, but the end result appears to be that products of sucrose metabolism via invertases vs sucrose synthases can initiate different sugar signals. These in turn are reflected in distinctive profiles of sugar-responsive gene expression.

SubCEllular SITES OF ACTION DIFFER. Enzymes encoded by genes for invertases and sucrose synthases can have different sites of action. Sucrose synthases are cytoplasmic, and are sensitive to metabolic modulation at the enzyme level [e.g., by phosphorylation (Koch et al., 1995; Huber et al., 1996; Zhang and Chollet, 1997; Winter et al., 1998) and other processes (Quick and Schaffer, 1996)]. In contrast, invertase gene products can be localized in the vacuole, cytoplasm, or cell wall compartments (Fig. 2). In yeast, individual invertase genes can be targeted to multiple sites (Carlson 1999), but in plants, different genes typically encode invertases bound for different subcellular locales (Lorenz et al., 1995; Sturm et al., 1995; Weber et al., 1995; Xu et al., 1996; Godt and Roitsch, 1997; Gallagher and Pollock, 1998; Talercio et al., 1999).

These plant invertases can be grouped by sequence similarity and correspond to previous protein classifications shown in Fig. 2 (Weber et al., 1995; Koch et al., 1996). Until recently it was not clear that distinctly separate genes were involved for cytoplasmic invertases, and activity of these enzymes varied greatly among different systems (Quick and Schaffer, 1996; Lee and Sturm, 1996; Walker et al., 1997; Gallagher and Pollock, 1998). Common features are typically evident among genes that encode vacuolar (soluble) proteins vs tightly bound cell-wall forms 
A

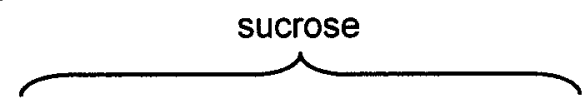

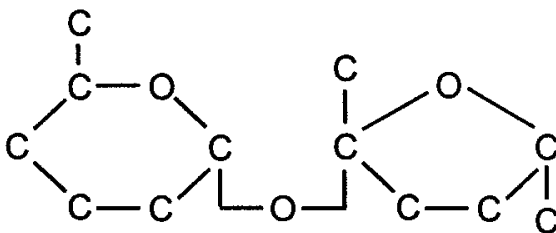
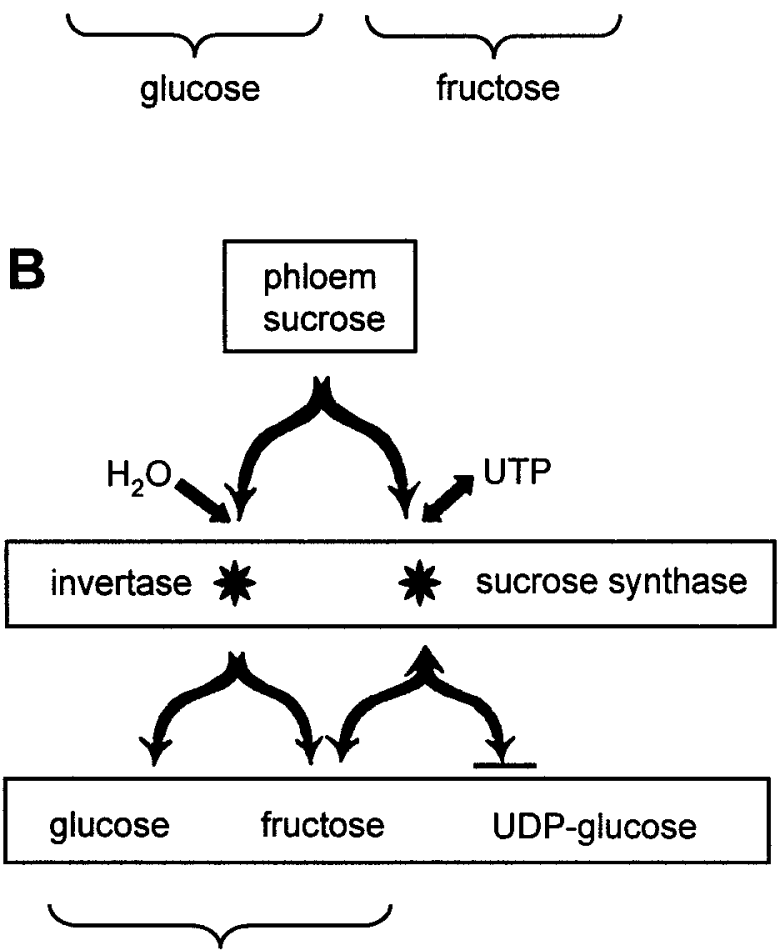

"sensible" by HK-linked sugar signaling

Fig. 1. The sucrose molecule (A) and the two known paths for its cleavage in higher plants (B). Note the difference in products of the invertase versus sucrose synthase reactions, particularly in their capacity to affect genes that respond to hexokinase-linked sugar signal transduction. HK = hexokinase, UDP-glucose $=$ uridine di-phospho-glucose, $\mathrm{UTP}=$ uridine tri-phosphate .

(insoluble) (Roitsch et al., 1995; Koch et al., 1996). Some soluble invertase proteins also may be secreted into the cell wall space, where a portion of the activity may remain loosely or minimally bound (Avigad, 1982; Quick and Schaffer, 1996). Both soluble and insoluble invertase gene products are heavily glycosylated (Quick and Schaffer, 1996), and those in the cell wall are subject to inhibition by a specific, extracellular protein apparently present in a number of plant species (Bracho and Whitaker, 1990; Pressey and Russel, 1994; Krausgrill et al., 1996; Greiner et al., 1997; 1999).

\section{Gene responses to sugar}

INDUCTION BY ABUNDANCE VS. DEPRIVATION; WHOLE-PLANT IMPLICATIONS. Specific plant genes can respond markedly to availability of sugars and these responses can vary widely depending on whether genes are being induced or repressed (Koch, 1996). Although such regulation has long been known in yeast and microorganisms (Koch, 1997; Smeekens and Rook, 1997; Carlson,
1999; Johnston, 1999), this possibility was recognized relatively recently for vascular plants. In microbial and single-celled systems such as algae, gene responses to sugars are part of an ancient mechanism for acclimation to the prevailing environment. Under $\mathrm{C}$-limited conditions, genes for $\mathrm{C}$ acquisition are up-regulated (e.g., induction of photosynthetic genes in algal systems) whereas with $\mathrm{C}$ abundance, genes for storage are induced (e.g., enhanced expression of genes for biosynthesis of starch and storage proteins).

Plant cells generally respond similarly (Koch et al., 1996; Jang and Sheen, 1997; Smeekens, 1998; Lalonde et al., 1999; Gibson, 2000); however, their individual sugar environments are determined by a combination of whole-plant carbohydrate status, extent of phloem sucrose delivery, and the path of sucrose arrival and metabolism. In addition, sugar signals are integrated with those of tissue and organ locale through modulation by other endogenous regulators. Among these interacting factors are hormones (Arenas-Huerero et al., 2000; Ehness and Roitsch, 1997a; Gazzarrini and McCourt, 2001; Huijser et al., 2000; Koch, 1996; Laby et al., 2000; Linden et al., 1996), nitrogen (Coruzzi and Bush, 2001; Koch, 1997; Stitt and Krapp, 1999), phosphorus (Sadka et al., 1994), and undoubtedly tissue-specific signals.

Collective responses are diagrammed in Fig. 3, where changes in relative source activity (C export) and sink activity ( $\mathrm{C}$ import) are shown to extend from the level of metabolism and gene expression to effects on $\mathrm{C}$ allocation between plant parts. Conditions of limited sugar availability can enhance source activity not only by enhancing photosynthetic gene expression (Koch, 1996; Jang and Sheen, 1997; Jang et al., 1997; Moore et al., 1999), but also by up-regulating genes for remobilization of stored carbohydrates [as in germinating seeds (Graham et al., 1994; Loreti et al., 2000; Reynolds and Smith, 1995; Thomas and Rodriguez, 1994)]. Subsequent export of sucrose to other plant parts is thus also favored when C availability is limited (Hesse et al., 1995; Koch, 1996). Conversely, photosynthetic genes are typically repressed by abundant sugar supplies. Resulting decreases in photosynthesis are typically observed over time (usually a few days) in instances where leaf carbohydrate levels increase after shifts in the source-sink balance (Geiger et al., 1996; Goldschmidt and Huber, 1992). These effects can be brought about by fruit thinning or $\mathrm{CO}_{2}$ enrichment, for example (Geiger et al., 1996). Responses to elevated $\mathrm{CO}_{2}$ involve initial rises in photosynthetic rates, partially due to effects on the RuBisCO reaction, yet much of this response is often countered by longer-term repression of genes for photosynthesis by changes in sugar status and/or shifts in C/N balance (Moore et al., 1999; Stitt and Krapp, 1999; Van Oosten and Besford, 1996). Although detrimental to plant C acquisition, this acclimation response process can benefit $\mathrm{C} / \mathrm{N}$

\section{Invertase locale}



Fig. 2. Types of invertase and their predominant subcellular localization. 


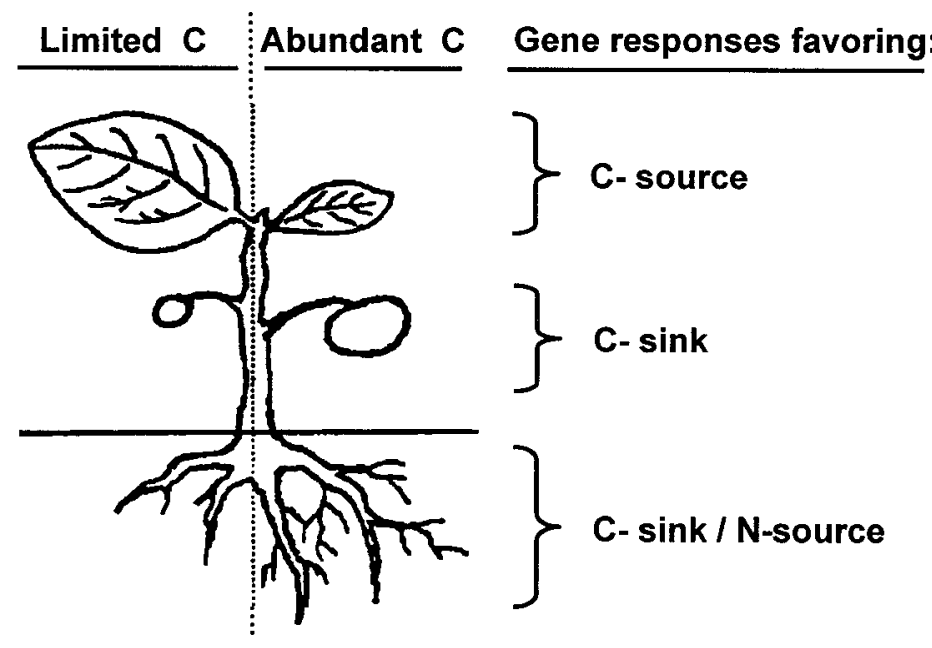

Fig. 3. Generalized representation of higher plant changes in gene expression under conditions of abundant versus limited $\mathrm{C}$ availability. Changes in whole plant balance between source (export) and sink (import) processes parallel changes that occur in microbial systems between $\mathrm{C}$ acquisition (autotrophy) and Cuse (heterotrophy). See text and Koch (1996) for additional information on an array of genes that extend from individual processes to developmental and morphological changes.

balance by facilitating redistribution of the $\mathrm{N}$ otherwise committed to photosynthetic proteins [RuBisCO, typically comprises about $40 \%$ of the soluble protein in leaves of C3 species (Sage et al, 1987)].

At the same time, genes affecting $\mathrm{C}$ demand by importing organs are down-regulated by limited carbon supplies, and upregulated when sugars are abundant (Koch, 1996). These genes encode proteins for biosynthesis of starch, cell walls, secondary metabolites (often active in pathogen resistance), and other storage constituents (Ehness et al., 1997b; Koch, 1996). In addition, plentiful sugar supplies can enhance expression of genes that alter shoot morphology (Tsai et al., 1997) and organ size (Weber and Wobus, 1997; Weber et al., 1998).

FEAST-OR-FAMINE GENES FOR SUCROSE USE. Genes for sucrose cleavage constitute what might initially appear to be an exception to the overall functional division described above (feast or famine induction of genes for $\mathrm{C}$ use or $\mathrm{C}$ acquisition, respectively). There are multiple invertases and sucrose synthases, typically encoded by different members of gene families, and analysis of their expression in maize has shown that there are sugar-enhanced and sugar-repressed forms of each (Koch et al., 1992; Xu et al., 1996).

The physiological significance of this dichotomy was initially perplexing, but sugar-induced shifts in sites of expression indicated a possible explanation (Koch et al., 1992; Koch and Nolte, 1995). Under conditions of plentiful sucrose supplies, sucrose synthases that respond positively to sugars (Susl in maize) were expressed throughout many cell types, favoring a broad-based import and use of sucrose. In contrast, sugar deprivation resulted in a shift to starvation-tolerant sucrose synthases ( $S h l$ in maize) and a marked narrowing of expression patterns that could theoretically confer an import priority to the most vital cells and tissues under stress (Koch et al., 1992, 1996). This potential is further supported by the restricted patterns of expression evident for the starvation-enhanced invertase genes in maize ( $I v r l)$ compared to their sugar-induced counterparts (Ivr2) (Xu et al., 1996). Data from other species are thus far also compatible with the possibility that starvation-tolerant genes for sucrose cleavage may have a generally more narrow pattern of expression and favor import by key cells and tissues under stresses (Heim et al., 1993; Koch et al., 1996; Martin et al., 1993).

Overall, evidence is consistent with a model in which carbohydrate feast or famine signals respectively favor genes for $\mathrm{C}$ use and import (sink) vs C acquisition and export (source). This framework appears to be equally applicable from single-cell to whole-plant levels, and also encompasses genes for $\mathrm{C} / \mathrm{N}$ balance (Coruzzi and Bush, 2001; Koch, 1996, 1997, 2000; Wang et al., 2000).

SigNALS FROM SUGARS TO RESPONSIVE GENES. The sugar sensing mechanism receiving the greatest attention as a possible effector in vascular plants is a hexokinase-based system that responds to hexoses rather than sucrose (Gibson, 2000; Koch, 1996, 2000; Jang and Sheen, 1997; Roitsch, 1999; Smeekens, 1998; Smeekens and Rook, 1997, 2000). Sucrose metabolism is central to responses by genes linked to a hexokinase path of sugar signaling. Signals are initiated at the first step in glycolysis, and require free hexoses (glucose, fructose, or other 6-C sugars). However, it is not the resultant hexose-P products that initiate the sugar signal, but an as-yet-undefined, second function of the hexokinase enzyme and/or reaction. This has been under investigation in an array of organisms from yeast to humans (Bell et al., 1996; Carlson, 2000; Jang and Sheen, 1997; Johnston 1999; Koch et al., 2000; Smeekens, 2000; Smeekens and Rook, 1997). It is important, because this mechanism provides a theoretical means of linking signal production to some aspect of metabolism rather than standing levels of any given sugar. Once the signal is initiated, it is transduced to responsive genes by a series of protein kinases and phosphatases that show marked similarities and important differences when compared to yeast systems (Halford, 1992; Jang and Sheen, 1997; Kim et al., 1997; Koch, 1997; Koch et al., 2000; Ohto and Nakamura, 1995; Smeekens, 2000; Smeekens and Rook, 1997). An additional complexity is the number of different hexokinases in higher plants and even different organs, with specific forms of gluco-kinases and fructo-kinases in fruit, for example (Kanayama et al., 1998; Martinez-Barajas et al., 1997; Martinez-Barajas and Randall, 1998; Pego and Smeekens, 2000). Further, results from other systems indicate that only some forms are active in sugar signal transduction [one of four glucokinases in humans, for example (Bell et al., 1996)]. Despite numerous unknowns about this system, it initiates signals from hexoses rather than sucrose or UDP-glucose.

Other hexose-responsive signaling systems have also been implicated in higher plants. Membrane sugar transfer in plants differs markedly from the sugar phosphotransferase system(PTS) in bacteria (Saier et al., 1995). Still, evidence indicates that yeast (Özcan et al., 1996) and plants may initiate sugar signals via membrane proteins homologous to glucose transporters (Hilgarth et al., 1991; Koch et al., 2000; Lalonde et al., 1999; Martin et al., 1997; Roitsch, 1999; Roitsch et al., 1995) For signaling via a glucose- or hexose-like transporter, invertase in the extracellular space has the potential to enhance substrate availability. Additional signaling systems appear likely for hexoses, based on studies in other organisms as well as plant gene responses that do not appear related to either membrane transfer or hexokinase action (Carlson, 2000; Jang and Sheen, 1997; Koch, 1996; Koch et al., 2000; Trumbley, 1992; Vaulont and Kahn, 1994).

Despite the importance of sucrose as a long-distance signal of carbohydrate status in higher plants, gene responses to sucrose per se have only recently been detected (Barker et al., 2000; Chiou and Bush, 1998; Lalonde et al., 1999; Loreti et al., 2000; Rook et al., 1998). Repressive effects of sucrose on gene expression 
predominate in most of the instances examined thus far [alphaamylase in barley embryos (Loreti et al., 2000), a sucrose transporter in phloem (Chiou and Bush, 1998; and unpublished data), and a transcription factor in Arabidopsis (Rook et al., 1998)], and appear linked to membrane-transporter-like activities.

A PIVOTAL ROLE FOR SUCROSE METABOLISM IN GENE EXPRESSION. The path of sucrose metabolism can thus affect expression of many genes by providing different substrates for signal transduction. The widespread influence of hexose-sensing mechanisms provides a means for invertase to amplify hexose-based sugar signals to a greater degree than does sucrose synthase (due to two times more hexose products from the invertase reaction) (Fig. 1B) (Koch, 1996; Koch et al., 1996, 2000). Evidence has indicated that both cell wall and vacuolar invertases can have marked effects on expression of hexose-responsive genes (Herbers and Sonnewald, 1998; Pachepsky et al., 1997; Sonnewald et al., 1991, Tang and Strum, 1999).

The invertase-sucrose synthase balance in a tissue can thus shift gene expression in several important ways. First, resulting changes in abundance of sucrose vs hexoses tend to favor general patterns of storage vs cell division and enlargement (Weber et al., 1995, 1996, 1998). In addition, rapid drops in the invertase/ sucrose synthase ratios under low oxygen stress (Zeng et al., 1998, 1999) favor down-regulation of hexose-responsive genes that may be costly under conditions of limited ATP supply. So too are transitions often observed from invertase to sucrose synthase during the course of organ development, and these coincide with shifts from cell division to storage phases. Examples include potato tubers (Sonnewald et al., 1997; Tauberger et al., 1999), maize kernels (Xu et al, 1996), and legume fruits and seeds (Geiger et al., 1996; Weber et al., 1998) [although invertase levels do rise in association with metabolic activity in some ripening fruit (D'Aoust et al., 1999) and cold-sweetening potatoes (Greiner et al., 1999)]. Finally, the genes for sucrose metabolism are themselves responsive to sugar signals (Ehness et al., 1997; Koch, 2000; Koch et al., 1992; Heim et al., 1993; Martin et al., 1993; Roitsch et al., 1995; Sturm et al., 1995; Xu et al., 1996), but it has not yet been definitively determined which respond to which sugar signals. It should be noted, however, that tissue sugar levels and types of sugars present may not affect sugar-responsive genes if the sugars are compartmentalized inside vacuoles or elsewhere away from the sensing systems.

\section{Molecular perturbation of genes for sucrose metabolism}

WHOLE-PLANT EXPRESSION AND SOURCE-SINK CONSIDERATIONS. An informative, though limiting aspect of the earliest experiments using invertase and sucrose synthase transgenics was a lack of organ-specific targeting. Whole plants were thus subjected to up-regulation of invertases throughout their source leaves as well as importing sink tissues (Table 1). Although Arabidopsis was minimally affected (von Schaewen et al., 1990), studies with tobacco (von Schaewen et al., 1990), tomato (Dickenson et al., 1991), and potato (Heineke et al., 1992), all showed strikingly detrimental effects of invertase over-expression in leaves. As photosynthetic capacity developed in the expanding leaves, they began to yellow, bleach, and/or show necrotic spots. Photosynthetic rates were also repressed and carbohydrate levels rose. In addition, internodes were shortened and fewer roots or other importing sinks were formed.

Several factors may contribute to these deleterious phenotypes. First, the whole plant characteristics are indicative of impaired photosynthate export, which could readily have resulted from action of extracellular invertase on sucrose moving through apoplastic export routes to the phloem. Second, repression of photosynthetic genes by hexoses (from invertase over-expression in this instance) has been demonstrated in species from algae to higher plants (Koch, 1996; Krapp et al., 1993; Sheen, 1990; Van Oosten and Besford, 1996). Analyses of the transgenic tobacco described above showed that photosynthetic enzyme activities were indeed reduced, and Stitt et al. (1990) likened this change to the classic sink effects on source leaves (altered photosynthetic rates linked to export and use by importing tissues). A third possibility lies in the potential for abundant hexoses in these transgenic plants to alter the metabolically important balance between sugar phosphates and inorganic phosphate (Büssis et al, 1997).

The potential for photosynthesis to be inhibited by a buildup of end-products in leaves was suggested over 100 years ago by Boussingault (1868) (discussed by Neale and Incoll, 1968), and more recent evidence confirms a role and probable mechanism for hexoses in this process. A similar process appears to affect the extent to which rising $\mathrm{CO}_{2}$ can enhance photosynthetic rates (Moore et al., 1999; Van Oosten and Besford, 1996) and leaf sugars in various species have the potential to affect this process (Goldschmidt and Huber, 1992). Although an important consideration for transgenic alterations is their effect on leaf sugars, it should also be noted that many species have endogenous leaf invertases that are active at considerably lower levels. In addition, expression of these endogenous invertases appears to be closely regulated during development, and/or specifically localized in different patterns that vary with species (Kingston-Smith and Pollock, 1996; Kingston-Smith et al., 1998). Carrot lines with strongly reduced expression of either soluble or cell wall invertases showed such deleteriously altered leaf and shoot phenotypes that exogenous hexose applications were necessary for initial recovery of viable plants (Sturm and Tang, 1999; Tang et al. 1999).

Transgenic approaches have also been used to alter sucrose synthase activity, and complement previous work with naturally occurring mutants that show locally reduced activity (e.g., in maize and pea). Like early studies with invertase transgenics, the first manipulations of sucrose synthase activity did not involve deliberate organ-level targeting. Responses to sucrose synthase antisense in tomato plants by D'Aoust et al. (1999 and unpublished data) were initially minimal due to the presence of multiple sucrose synthase genes throughout the plant. However, later work with more fruit-specific reductions in gene expression reduced fruit number (discussed further below) (D'Aoust et al., 1999). An early set of transgenic studies with antisense sucrose synthase was also undertaken in potato, and since it resulted in tuberspecific reductions in activity (Zrenner et al., 1995), results are discussed with other organ-specific experiments below.

TARGETED CHANGES IN EXPRESSION OF GENES FOR SUCROSE METABOLISM. Subcellular compartmentation: The first set of targeted expression studies for genes of sucrose metabolism came at the level of subcellular compartmentalization rather than at the organ level (Table 1). Important and intriguing information has arisen from these studies, as well as development of the tools needed to combine these manipulations with others (described further below). The initial work with transgenic tobacco and potato (noted above) involved targeting a yeast invertase to the cell wall compartments throughout the plant. Localization was then expanded to include specific vacuolar and cytoplasmic compartments (Sonnewald et al., 1991). All three types of resulting plants were stunted, with limited root development and leaves 
that had yellow regions, bleaching, and/or necrotic spots. However, plants with cytoplasmically targeted invertase showed early onset of a more uniform leaf yellowing that was not linked to photosynthetic maturation. Subsequent analyses have indicated further contrasts between these plants. Transgenics with elevated invertase expression in vacuoles or cell walls, but not cytoplasm, showed repression of photosynthetic genes and concurrent upregulation of genes for pathogen related (PR) proteins (Herbers and Sonnewald, 1998). Differences in effects on signaling pathways by invertase products from different compartments have been suggested, but underlying mechanisms are currently unclear and appear more complex than existing models.

Table 1. Direct transgenic alterations of genes for sucrose metabolism.

\begin{tabular}{|c|c|c|c|}
\hline Target and enzyme & Gene expression & Species & Result \\
\hline \multicolumn{4}{|l|}{ Entire plant } \\
\hline \multirow[t]{5}{*}{ Invertase } & Overexpression & Arabidopsis & Stunted, leaves yellow, senesce early \\
\hline & & Tobacco & A sick leaf phenotype (yellow and/or bleached sectors + necrotic spots) \\
\hline & & & Limited root and sink development \\
\hline & & Potato & Same as above \\
\hline & & Tomato & Same as above \\
\hline \multicolumn{4}{|c|}{ Entire plant, but specific subcellular sites } \\
\hline Sucrose synthase & Antisense & Carrot & $\begin{array}{l}\text { Tap roots with more sucrose, but less hexoses, less starch, less cellulose } \\
\text { Smaller leaves and roots }\end{array}$ \\
\hline Cytoplasmic invertase & Overexpression & Potato & $\begin{array}{l}\text { Leaf phenotype more uniform yellow than for potato above, and early } \\
\text { onset not linked to photosynthesis } \\
\text { No effect on genes for pathogen-related (PR) proteins, but induction of of } \\
\text { some for water stress } \\
\text { Elevated levels of sugar-P; water stress symptoms }\end{array}$ \\
\hline \multirow[t]{6}{*}{ Cell-wall invertase } & Overexpression & Potato & Same morphology as for potato above \\
\hline & & & $\begin{array}{l}\text { Repression of photosynthetic genes, induction of pathogen-related (PR) } \\
\text { proteins } \\
\text { Water stress symptoms }\end{array}$ \\
\hline & & Tobacco & Few secondary plasmodesmata form \\
\hline & Antisense & Carrot & Fused-leaf anomalies in cultured plantlets \\
\hline & & & More leaves, higher levels of leaf carbohydrates \\
\hline & & & No taproots formed, other roots have less soluble sugar and starch \\
\hline \multirow[t]{7}{*}{ Vacuolar invertase } & Overexpression & Tobacco & Increased leaf cell wall diameter and cell turgor \\
\hline & & & Reduced cell area index, stomatal apperture + transpiration \\
\hline & & Potato & Same morphology as for potato above \\
\hline & & & Water stress symptoms; reduced transpiration + gas exchange \\
\hline & Antisense & Potato & When cold-induced, sucrose/hexose ratio up; total soluble sugars change little \\
\hline & & Carrot & Fused-leaf anomalies in cultured plantlets \\
\hline & & & Smaller taproots, less soluble sugars \\
\hline \multicolumn{4}{|c|}{ Specific sink and subcellular sites } \\
\hline \multicolumn{4}{|l|}{ Tuber } \\
\hline Sucrose synthase & Antisense & Potato & Tuber starch down, invertase and soluble sugars up; tuber number same \\
\hline Cytoplasmic invertase & Overexpression & Potato & $\begin{array}{l}\text { Long tubers with many lenticels } \\
\text { High glucose/sucrose in maturing tubers, but turgor down } \\
\text { Starch grain number same, but smaller }\end{array}$ \\
\hline Cell-wall invertase & Overexpression & Potato & $\begin{array}{l}\text { A } 50 \%-300 \% \text { increase in tuber size }(\mathrm{FW}) \text {; reduced number } \\
\text { High glucose/sucrose in maturing tubers, turgor up, cell size same } \\
\text { Starch grain number same, but smaller }\end{array}$ \\
\hline Vacuolar invertase & Overexpression & Potato & $\begin{array}{l}\text { Tuber number up } 50 \%-250 \% \\
\text { Small potatoes }\end{array}$ \\
\hline Invertase inhibitor & Overexpression & Potato & $\begin{array}{l}\text { (Targeted to vacuole) Prevented cold sweetening of tubers without reducing } \\
\text { yield, starch quantity, or starch quality }\end{array}$ \\
\hline \multicolumn{4}{|l|}{ Fruit } \\
\hline Sucrose synthase & Antisense & Tomato & $\begin{array}{l}\text { Reduced fruit set from earliest flowers (first tomato flowers often sink-limited) } \\
\text { Overall yield reduced }\end{array}$ \\
\hline Vacuolar invertase & Antisense & Tomato & $\begin{array}{l}\text { Fruit small, sucrose up, hexoses down } \\
\text { Same as above (specific vac targeting) }\end{array}$ \\
\hline \multicolumn{4}{|r|}{ 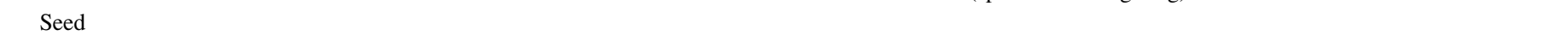 } \\
\hline Cell-wall invertase & Overexpression & Broadbean & Less sucrose, more hexoses \\
\hline & & & Larger vacuoles; wrinkled seeds \\
\hline & & & Little change in storage protein \\
\hline & & & Less starch and sucrose synthase \\
\hline
\end{tabular}


Pieces of this puzzle regarding effects of different subcellular sites for invertase overexpression are likely to lie in further analysis of signaling mechanisms, and also in specific features of these transgenic plants. Ding et al. (1993), for example, found that invertase overexpression inhibited formation of secondary plasmodesmata, which they suggested may in turn limit transfer of

Citation

von Schaewen et al., 1990

von Schaewen et al., 1990

Heineke et al., 1992

Dickenson et al., 1991

Tang and Sturm, 1999; Sturm and Tang, 1999

Sonnewald et al., 1991

Herbers and Sonnewald, 1998

Büssis et al., 1997

von Schaewen et al., 1990; Sonnewald et al., 1991

Herbers et al., 1996; Herbers and Sonnewald, 1998

Büssis et al., 1997

Ding et al., 1993

Tang et al., 1999

Sturm and Tang, 1999

Hoffmann-Benning et al. 1997

Pachepsky et al., 1997

Sonnewald et al., 1991

Herbers and Sonnewald, 1998; Büssis et al., 1997

Zrenner et al., 1996

Tang et al., 1999

Strum and Tang, 1999

Zrenner et al., 1995

Sonnewald, 1994

Tauberger et al., 1999

Sonnewald et al., 1997

Tauberger et al., 1999

Sonnewald, et al., 1997

Greiner et al., 1999

D’Aoust et al., 1999

Ohyama et al., 1995

Klann et al., 1996

Weber et al. 1998 molecular information affecting leaf development. Each of the invertase transgenics also displayed symptoms of water stress, regardless of targeted compartment (Büssis et al., 1997). For those with elevated cytoplasmic invertase, enhanced expression of water-stress-related proteins was evident (Herbers and Sonnewald, 1998). Where invertase overexpression was targeted to the vacuole, water stress symptoms were particularly apparent in reduced transpiration (Pachepsky et al., 1997). In this instance, effects of smaller stomatal apertures were also accompanied by the influence of structural alterations such as reduced cell area index (contributing to about $25 \%$ of the reduced water loss) (Pachepsky et al., 1997). Nonetheless, this limitation in gas exchange was estimated to account for only a small portion of the photosynthetic reduction in these plants (Pachepsky et al., 1997). Finally, despite the typical reduction of photosynthetic gene expression by treatments such as those employed in these studies, Büssis et al. (1997) suggested that RuBisCO in these instances may also be inhibited at the level of activation. Their data also indicated that at least in plants with excesses of vacuolar and cytoplasmic invertases, hexose products of these reactions may exert a metabolic effect that operates by tying up critical supplies of inorganic phosphorus as sugar-P intermediates.

Organ level targeting: Results are now available from studies in which genes for sucrose metabolism have been targeted to sink tissues (Table 1). The first of these arose from studies in which a specific potato gene for sucrose synthase was antisensed throughout the plant, but reductions in activity were observed to be restricted to the tubers (Zrenner et al., 1995). This work showed anticipated reductions in starch levels, but also marked increases in hexose levels and invertase activity (40×). The latter was not accompanied by expected increases in tuber number. The basis for this remains unclear, but tuber metabolism responds quite differently to glucose versus sucrose (Geiger et al., 1998). Antisense methods were also employed to study contributions by a cold-inducible invertase during tuber responses to low temperature (Zrenner et al., 1996). Results indicated that this invertase was not responsible for the deleterious increases in soluble sugar levels during cold storage, but it did have a marked role in determining hexose to sucrose ratios.

A similar approach resulted in essentially sink-specific responses in antisense studies of vacuolar invertases in tomato (Klann et al., 1996; Ohyama et al., 1995). Although plant growth was identical for wild-type and transgenic plants, the lines in which a specific vacuolar invertase was most reduced showed the most pronounced changes in fruit sugars and size (Klann et al., 1996). Where vacuolar invertase was least active, fruit sucrose levels were consistently higher, hexoses lower, and fruit size smaller. A prominent role for this gene and enzyme was thus identified in both fruit size and composition.

Sucrose synthase activity was also successfully reduced in tomato fruit with minimal effects elsewhere in the plant (D'Aoust et al., 1999). In this material, fruit set was reduced for the first crop of tomatoes harvested from the plants (when source/sink ratio was greatest). This and other data indicated a role for sucrose synthase during the earliest phase of tomato fruit growth.

Successful increase in sink size was achieved in potato tubers by a combination of cell- and organ-specific targeting of invertase (Sonnewald et al., 1997). Tuber size was increased 50\% to 300\% on a fresh weight basis when invertase was overexpressed in the apoplast of the tubers. The greatest increases in tuber size were associated with the strongest invertase expression, but also with the most pronounced reductions in tuber number. Overall tuber 
weight per plant was not significantly altered. Although results from individual tubers demonstrate an exciting principle for future use, whole plant results in this species support calculations indicating potato productivity may be source-limited rather than sink limited (Sweetlove et al., 1998). Interestingly, when invertase overexpression was targeted to tuber vacuoles, tuber number rather than size increased (rising by $50 \%$ to $250 \%$ ) (Sonnewald et al., 1997). In addition, cytoplasmic targeting of elevated invertase led to atypically long tubers, with many lenticels (Sonnewald et al., 1994).

Metabolic engineering, using altered expression of more than one gene, has now also included genes for sucrose cleavage. Since studies showed that tuber size could be increased by overexpressing invertase in the cell wall space, a further goal was to direct some of the hexose production from this reaction into starch biosynthesis. Toward this end, glucokinase was introduced as a second transgene into this system (Trethewey et al., 1998) but resulting C flux favored respiration rather than starch synthesis. Both genes together reduced starch content to as low as $35 \%$ of wild-type levels.

Indirect manipulation of genes for sucrose metabolism has also been employed in transgenic approaches. An unexpectedly positive response on sucrose synthase activity and starch storage was observed in potato tubers when pyrophosphatase was overexpressed specifically in these organs (Geigenberger et al., 1998). Based on earlier studies of overexpression throughout the plant, decreases in pyrophosphate levels were expected to reduce C flux through the sucrose synthase reaction by inhibiting use of the UDP-glucose produced (Stitt and Sonnewald, 1995). Instead, these experiments indicate that pyrophophosphate can have a stimulatory effect on starch biosynthesis and gene expression when manipulated in a sink-specific manner.

Another of these indirect effectors was employed in a transgenic study to induce parthenocarpy in tobacco and eggplant (Rotino et al., 1997). Desired results were achieved by combining an ovule-specific promoter with a gene that gives rise to elevated levels of endogenous IAA. Transgenic plants set fruit under stresses that prevented fertilization in wildtype plants. Presumably one or more genes for sucrose metabolism and import were up-regulated in the process.

\section{Developmental considerations}

Despite a wealth of research indicating the importance of developmental changes in invertase and sucrose synthase activity, the molecular materials for utilizing this information have remained limited. The capacity to turn genes for sucrose metabolism on and off at specific points in time is likely to be at least as important as that of directing sites of expression. Soluble invertases for example are turned on only during narrow windows of early development and fruit set for bean (Geiger et al., 1996) and corn (Xu et al., 1996), at the midperiod of development for grape (Davies et al., 1997) and later in development for tomato (Klann et al., 1996). It is possible that successful transgenic manipulation of the potato tubers described above requires not only the early enhancement of soluble invertase activity (which leads to initiation and early development of many tubers), but an equally important down-regulation thereafter. This hypothesis is consistent with the work of Weber et al. (1998), which indicates that elevated invertase and hexose levels may favor cell division in developing bean seeds, whereas later invertase reductions and relative increases in sucrose favor differentiation. In addition, studies with a mutant alfalfa line have indicated that downregulation of an invertase normally active during leaf expansion must occur before leaf maturation, or a deleterious phenotype will result (Das et al., 1998). The latter has similarities to the invertase overexpressing transgenics. Finally, during maize kernel development, activity of sucrose synthase appears to move across the endosperm in concert with developmental waves of cellular maturation and starch synthesis (Wittich and Vreugdenhil, 1998). Optimal manipulation of genes for sucrose metabolism in a developmental and tissue context is likely to require considerable refinement of existing methodologies, but advances thus far have shown promise.

\section{Literature Cited}

Arenas-Huertero, F., A. Arroyo, L. Zhou, J. Sheen, and P. Leon. 2000. Analysis of Arabidopsis glucose insensitive mutants, gin5 and gin6, reveals a central role for the plant hormone $\mathrm{ABA}$ in the regulation of plant vegetative development by sugar. Genes Dev. 14:2085-2096.

Avigad, G. 1982. Sucrose and other disaccharides, p. 217-347. In: Loewus and W. Tanner (eds.). Encyclopedia of plant physiology. vol. 13A. FA. Springer Verlag, Heidelberg.

Barker, L., C. Juhn, A. Weise, C. Gebhardt, B. Hirner, H. Hellmann, W. Schulze, J.M.Ward, and W.B. Fromer. 2000. SUT2, a putative sucrose sensor in sieve elements. Plant Cell 12:1153-1164.

Bell, G.I., S.J. Pilkis, I.T. Weber, and K.S. Polonsky. 1996. Glucokinase mutations, insulin secretion, and diabetes mellitus. Annu. Rev. Physiol. 58:171-186.

Boussingault, J.B. 1868. Agronomie, chime agricole et physiologic. $2^{\text {nd }}$ ed. Mallet Bachelier, Paris. p. 236-312.

Bracho, G.E. and J.R. Whitaker. 1990. Purification and partial characterization of potato (Solanum tuberosum) invertase and its endogenous proteinaceous inhibitor. Plant Physiol. 92:386-394.

Büssis, D., D. Heineke, U. Sonnewald, L. Willmitzer, K. Raschke, and H.W. Heldt. 1997. Solute accumulation and decreased photosynthesis in leaves of potato plants expressing yeast-derived invertase either in the apoplast, vacuole or cytosol. Planta 202:126-136.

Carlson, M. 1999. Glucose repression in yeast. Current Opin. Microbiol. 2:202-207.

Chiou, T.J. and D.R. Bush. 1998. Sucrose is a signal molecule in assimilate partitioning. Proc. Natl. Acad. Sci. USA 95:4784-4788.

Coruzzi, G. and D.R. Bush. 2001. Nitrogen and carbon nutrient and metabolite signaling in plants. Plant Physiol. 125:61-64.

D’Aoust, M.A., S. Yelle, and B. Nguyen-Quoc. 1999. Antisense inhibition of tomato fruit sucrose synthase decreases fruit setting and the sucrose unloading capacity of young fruit. Plant Cell 11:2407-2418.

Das, S.D., S.R. Bowley, and B.D. McKersie. 1998. A high-leaf starch mutant in alfalfa has altered invertase activity. Crop Sci. 38:722-728. Davies, C., P.K. Boss, and S.P. Robinson. 1997. Treatment of grape berries, a nonclimacteric fruit with a synthetic auxin, retards ripening and alters the expression of developmentally regulated genes. Plant Physiol. 115:1155-1161.

Delmer, D.P. and Y. Amor. 1995. Cellulose biosynthesis. Plant Cell 7:987-1000.

Dickinson, C.D., T. Altabella, and M.J. Chrispeels. 1991. Slow-growth phenotype of transgenic tomato expressing apoplastic invertase. Plant Physiol. 95:420-425.

Ding, B., J.S. Haudenshield, L. Willmitzer, and W.J. Lucas. 1993. Correlation between arrested secondary plasmodesmal development and onset of accelerated leaf senescence in yeast acid invertase transgenic tobacco plants. Plant J. 4:179-189.

Ehness, R. and T. Roitsch. 1997a. Coordinated induction of mRNAs for extracellular invertase and a glucose transporter in Chenopodium rubrum by cytokinins. Plant J. 11:539-548.

Ehness, R. and T. Roitsch. 1997b. Differential effect of D-glucose on the level of messenger-RNAs for 3 invertase isoenzymes of Chenopodium rubrum. J. Plant Physiol. 150:514-519.

Ehness, R., M. Ecker, D.E. Godt, and T. Roitsch. 1997. Glucose and stress independently regulate source and sink metabolism and defense- 
mechanisms via signal-transduction pathways involving protein-phosphorylation. Plant Cell 9:1825-1841.

Gallagher, J.A. and C.J. Pollock. 1998. Isolation and characterization of a cDNA clone from Lolium temulentum L. encoding for a sucrose hydrolytic enzyme which shows alkaline/neutral invertase activity. J. Expt. Bot. 49:789-795.

Gazzarrini. S. and P. McCourt. 2001. Genetic interactions between ABA, ethylene and sugar signaling pathways. Curr pin Plant Biol 4:387-391.

Geigenberger, P., M. Hajirezaei, M. Geiger, U. Deiting, U. Sonnewald, and M. Stitt. 1998. Overexpression of pyrophosphatase leads to increased sucrose degradation and starch synthesis, increased activities of enzymes for sucrose-starch onterconversions, and inreased levels of nucleotides in growing potato tubers. Planta 205:428-437.

Geiger, D.R., K.E. Koch, and W.J. Shieh. 1996. Effect of environmental factors on whole-plant assimilate partitioning and associated gene expression. J. Expt. Bot. 47:1229-1238.

Gibson, S.L. 2000. Plant sugar-response pathways. Part of a complex regulatory web. Plant Physiol. 124:1532-1539.

Godt, D.E. and T. Roitsch. 1997. Regulation and tissue-specific distribution of messenger-RNAs for 3 extracellular invertase isoenzymes of tomato suggests an important function in establishing and maintaining sink metabolism. Plant Physiol. 115:273-282.

Goldschmidt, E.E. and S.C. Huber. 1992. Regulation of photosynthesis by end-product accumulation in leaves of plants storing starch, sucrose, and hexose sugars. Plant Physiol. 99:1443-1448.

Graham, I.A., K.J. Denby, and C.J. Leaver. 1994. Carbon catabolize repression regulates glyoxylate cycle gene-expression in cucumber. Plant Cell 6:761-772.

Greiner, S., S. Krausgrill, K. Herbers, U. Sonnewald, and T. Rausch. 1997. Cloning of a novel class of cell-wall invertase binding-proteins invertase inhibitors or regulatory subunits. Plant Physiol. 114:320 (abstr.).

Greiner, S., T. Rausch, U. Sonnewald, and K. Herbers. 1999. Ectopic expression of a tobacco invertase inhibitor homolog prevents coldinduced sweetening of potato tubers. Nature Biotechnol. 17:708-711.

Halford, N.G., J. Vincente-Carbajosa, P.A. Sabrelli, P.R. Shrewry, U. Hannippel, and M. Kreis. 1992. Molecular analyses of a barley multigene family homologous to the yeast protein kinase gene SNF1. Plant J. 2:791-797.

Heim, U., H. Weber, H. Bäumlein, and U. Wobus. 1993. A sucrosesynthase gene of Vicia faba L.: Expression pattern in developing seeds in relation to starch synthesis and metabolic regulation. Planta 191:394 401.

Heineke, D., U. Sonnewald, D. Büssis, G. Günter, K. Leidreiter, I. Wilke, K. Rauschke, L. Willmitzer, and H.W. Heldt.1992. Apoplastic expression of yeast-derived invertase in potato: Effects on photosynthesis, leaf solute composition, water relations, and tuber composition. Plant Physiol. 100:301-308.

Herbers, K., P. Meuwly, W. Frommer, J.P. Metraux, and U. Sonnewald. 1996. Systemic acquired resistance mediated by the ectopic expression of invertase: possible hexose sensing in the secretory pathway. Plant Cell 8:793-803.

Herbers, K. and U. Sonnewald. 1998. Altered gene expression brought about by inter- and intracellularly formed hexoses and its possible implications for plant-pathogen interactions. J. Plant Res. 111: 323 328.

Hesse, H., U. Sonnewald, and L. Willmitzer. 1995. Cloning and expression analysis of sucrose-phosphate-synthase from sugar beet (Beta vulgaris L.). Mol. Gen. Genet. 247:515-520.

Hilgarth, C., N. Sauer, and W. Tanner. 1991. Glucose increases the expression of the ATP/ADP translocator and the glyceraldehyde-3phosphate dehydrogenase genes in Chlorella. J. Biol. Chem. 266:2404424047.

Hoffmann-Benning S., L. Willmitzer, and J. Fishan. 1997. Analysis of growth, composition, and thickness of the cell wall of transgenic tobacco plants expression a yeast-derived invertase. Protoplasma 200:146-153.
Huber, S.C., J.L. Huber, P.C. Liao, D.A. Gage, R.W. McMichael Jr., P.S. Chourey, L.C. Hannah, and K.E. Koch. 1996. Phosphorylation of serine-15 of maize leaf sucrose synthase. Plant Physiol. 112:793-802.

Huijser, C., A. Kortstee, J. Pego, P.Weisbeck, E Wisman, and S. Smeekens. 2000. The Arabidopsis SUCROSE UNCOUPLED-6 gene is identical to ABSCISIC ACID INSENSITIVE-4: Involvement of abscisic acid in sugar responses. Plant J. 23:577-585.

Jang, J-C. and J. Sheen. 1997. Sugar sensing in higher plants. Trends Plant Sci. 2(6):208-214.

Jang, J-C., P. Leon, L. Zhou, and J. Sheen. 1997. Hexokinase as a sugar sensor in higher plants. Plant Cell 9:5-19.

Johnston, M. 1999. Feasting, fasting, and fermenting. Glucose sensing in yeast and other cells. Trends Genet. 15:29-33.

Kanayama, Y., D. Granot, N. Dai, M. Petreikov, A. Schaffer, A. Powell, and A.B. Bennet. 1998. Tomato fructokinases exhibit differential expression and substrate regulation. Plant Physiol. 117:85-90.

Kim, D.J., S.M. Smith, and C.J. Leaver. 1997. A cDNA encoding a putative SPF1-type DNA-binding protein from cucumber. Gene 185:265-269.

Kingston-Smith, A.H., N. Galtier, C.J. Pollock, and C.H. Foyer. 1998. Soluble acid invertase activity in leaves is independent of speciesdifferences in leaf carbohydrates, diurnal sugar profiles and paths of phloem loading. New Phytol. 139:282-294.

Kingston-Smith, A.H. and C.J. Pollock. 1996. Tissue level localization of acid invertase in leaves: A hypothesis for the regulation of carbon export. New Phytol. 134:423-432.

Klann, E.M., B. Hall, and A.B. Bennett. 1996. Antisense acid invertase (TIV1) gene alters soluble sugar composition and size in transgenic tomato fruit. Plant Physiol. 112:1321-1330.

Koch, K.E. 1997. Molecular crosstalk and the regulation of C- and Nresponsive genes, p. 105-124. In: C. Foyer and P. Quick (eds.). A molecular approach to primary metabolism in plants. Taylor and Francis Inc., London.

Koch, K.E. 1996. Carbohydrate-modulated gene expression in plants. Annu. Rev. Plant Physiol. Plant Mol. Biol. 47:509-540.

Koch, K.E., Y. Wu, and J. Xu. 1996. Sugar and metabolic regulation of genes for sucrose metabolism: Potential influence of maize sucrose synthase and soluble invertase responses on carbon partitioning and sugar sensing. J. Expt. Bot. 47:1179-1185.

Koch, K.E. and K.D. Nolte. 1995. Sugar-modulated expression of genes for sucrose metabolism and their relationship to transport pathways, $\mathrm{p}$. 141-155. In: M.M. Madore and W.L. Lucas (eds.). Carbon partitioning and source-sink interactions in plants. Amer. Soc. Plant Physiol., Rockville, Md.

Koch, K.E., J. Xu, E.R. Duke, D.R. McCarty, C.X. Yuan, B.C. Tan, and W.T. Avigne. 1995. Sucrose provides a long distance signal for coarse control of genes affecting its metabolism, p. 266-277. In: H.D. Pontis, G.L. Salerno, and E. Echeverria (eds.). Sucrose metabolism, biochemistry, and molecular biology. Amer. Soc. Plant Physiol, Rockville, Md. Koch, K.E., K.D. Nolte, E.R. Duke, D.R. McCarty, and W.T. Avigne. 1992. Sugar levels modulate differential expression of maize sucrose synthase genes. Plant Cell 4:59-69.

Koch, K.E., Y. Zing, Y. Wu, and W.T. Avigne. 2000. Multiple paths of sugar-sensing and a sugar/oxygen overlap for genes of sucrose and ethanol metabolism. J. Expt. Bot. 51:417-427.

Krapp, A, B. Hofmann, C. Schäfer, and M. Stitt. 1993. Regulation of the expression of rbcS and other photosynthetic genes by carbohydrates: A mechanism for the "sink regulation" of photosynthesis? Plant J. 3:817828.

Krausgrill, S., A. Sander, S. Greiner, M. Weil, and T. Rausch. 1996. Regulation of cell-wall invertase by a proteinaceous inhibitor. J. Expt. Bot. 47:1193-1198.

Laby, R.J., M.S. Kincaid, D. Kim, and S.I. Gibson. 2000. The Arabidopsis sugar-insensitive mutants sis4 and sis5 are deective in abscisic acid synthesis and response. Plant J. 23:587-596.

Lalonde, S., E. Boles, H. Hellmann, L. Barker, J.W. Patrick, W.B. Frommer, and J.M. Ward. 1999. The dual function of sugar carriers: Transport and sugar sensing. Plant Cell 11:707-726. 
Lee, H.S. and A. Sturm. 1996. Purification and characterization of neutral and alkaline invertase from carrot. Plant Physiol. 112:15131522.

Linden, J.C., R. Ehness, and T. Roitsch. 1996. Ethylene regulation of apoplastic invertase expression in autotrophic cells of Chenopodium rubrum. Plant Growth Regulat. 19:219-222.

Lorenz, K., S. Lienhard, and A. Sturm. 1995. Structural organization and differential expression in carrot beta-fructofuranosidase genes: Identification of a gene coding for a flower bud-specific isozyme. Plant Mol. Biol. 28:189-194.

Loreti, E., A. Alpi, and P. Perata. 2000. Glucose and disaccharidesensing meahanisms modulate the expression of alpha-amylase in barley embryos. Plant Physiol. 123:939-948.

Martin, T., H. Hellmann, R. Schmidt, L. Willmitzer, and W.B. Frommer. 1997. Identification of mutants in metabolically regulated gene expression. Plant J. 11:53-62.

Martin, T., W.B. Frommer, M. Salanoubat, and L. Willmitzer. 1993. Expression of an Arabidopsis sucrose synthase gene indicates a role in metabolization of sucrose both during phloem loading and in sink organs. Plant J. 4:367-377.

Martinez-Barajas, E. and D.D. Randall. 1998. Purification and characterization of a glucokinase from young tomato (Lycopersicon esculentum L. Mill.) fruit. Planta 205:567-573.

Martinez-Barajas, E., M.H. Luethy, and D.D. Randall. 1997. Molecular cloning and analysis of fructokinase expression in tomato (Lycopersicon esculentum Mill.). Plant Sci. 125:13-20.

Moore, B.D., S.-H. Cheng, D. Sims, and J.R. Seeman. 1999. The biochemical and molecular basis for photosynthetic acclimation to elevated $\mathrm{CO}_{2}$. Plant Cell Environ. 22:567-582.

Morris, D.A. and E.D. Arthur. 1984. Invertase and auxin-induced elongation in internodal segments of Phaseolus vulgaris L. Phytochemistry 23:2163-2167.

Neales, T.F. and L.D. Incoll. 1968. The control of leaf photosynthesis rate by the level of assimilate concentration in the leaf: A review of the hypothesis. Bot. Rev. 34:107-125.

Nolte, K.D., D.L. Hendrix, J.W. Radin, and K.E. Koch. 1995. Sucrose synthase localization during initiation of seed development and trichrome differentiation in cotton ovules. Plant Physiol. 109:12851293.

Ohto, M.A. and K. Nakamura. 1995. Sugar-induced increase of calciumdependent protein kinases associated with the plasma membrane in leaf tissues of tobacco. Plant Physiol. 109:973-981.

Ohyama, A., H. Ito, T. Sato, S. Nighimura, T. Imai, and M. Hirai.1995. Suppression of acid invertase activity by antisense modifies the sugar composition of tomato fruit. Plant Cell Physiol. 36:369-376.

Özcan, S., J. Dover, A.G. Rosenwald, S. Wolfl, and M. Johnston. 1996. Two glucose transporters in Saccharomyces cerevisiae are glucose sensors that generate a signal for induction of gene expression. Proc. Natl. Acad. Sci. USA 93:1-5.

Pachepsky, L.B., B. Acock, S. Hoffman-Benning, L. Willmitzer, and J Fisahn. 1997. Estimation of the anatomical, stomatal and biochemical components of differences in photosynthesis and transpiration of wildtype and transgenic (expressing yeast-derived invertase targeted to the vacuole) tobacco leaves. Plant Cell Environ. 20:1070-1078.

Pego, J.V. and S.C. Smeekens. 2000. Plant fructokinases: A sweet family get-together. Trends Plant Sci. 5:531-536.

Perata, P., L. Guglielminetti, and A. Alpi. 1997. Mobilization of endosperm reserves in cereal seeds under anoxia. Ann. Bot. 79:49-56.

Pressey, R. 1994. Invertase inhibitor in tomato fruit. Phytochemisrty 36:543-546.

Quick, P.W. and A.A. Schaffer. 1996. Sucrose metabolism in sources and sinks. In: E. Zamski and A.A. Schaffer (eds.). Photoassimilate distribution in plants and crops: Source-sink relationships. Marcel Dekker, Inc., New York.

Reynolds, S.J. and S.M. Smith. 1995. Regulation of expression of the cucumber isocitrate lyase gene in cotyledons upon seed germination and by sucrose. Plant Mol. Biol. 29:885-896.

Riou-Khamlichi, C., Menges, M., J.M. Healy, and J.A. Murray. 2000.
Sugar control of plant cell cycle: differential regulation of Arabidopsis D-type cyclin gene expression. Mol Cell Biol. 20:4513-4521.

Roitsch, T., M. Bittner, and D.E. Godt. 1995. Induction of apoplastic invertase of Chenopodium rubrum by D-glucose and a glucose analogue and tissue specific expression suggest a role in sink-source regulation. Plant Physiol. 108:285-294.

Roitsch, R. 1999. Source-sink regulation by sugar and stress. Curr. Opin. Plant Biol. 2:198-206.

Rook, F., N. Gerrits, A Kortstee, M. Van Kampen, M. Borrias, P. Weisbeek, and S. Smeekens.1998. Sucrose-specific signalling represses translation of the Arabidopsis ATB2 bZIP transcription factor gene. Plant J. 15:253-263.

Rotino, G.L., E. Perri, M. Zottini, H. Sommer, and A. Spena. 1997. Genetic engineering of parthenocarpic plants. Nature Biotechnol. 15:1398-1401.

Sadka, A., D.B. DeWald, G.D. May, W.D. Park, and J.E. Mullet. 1994. Phosphate modulates transcription of soybean VspB and other sugarinducible genes. Plant Cell 6:737-749.

Sage, R.F., R.W. Pearcy, and N.R. Seemann. 1987. The nitrogen use efficiency of $\mathrm{C} 3$ and $\mathrm{C} 4$ plants III: Leaf nitrogen effects on the activity of carboxylating enzymes in Chenopodium album L. and Amaranthus retroflexus L. Plant Physiol. 85:355-359.

Saier, M.H., S. Chauvaux, J. Deutscher, J. Reizer, and J.J. Ye. 1995. Protein phosphorylation and regulation of carbon metabolism in Gramnegative vs. Gram-positive bacteria. Trends Biochem. Sci. 20:267271.

Sheen, J. 1990. Metabolic repression of transcription in higher plants. Plant Cell 2:1027-1038.

Smeekens, S.C.M. 1998. Sugar regulation of gene expression in plants. Current Opin. Plant Biol. 1:230-234.

Smeekens, S.C.M. 2000. Sugar-induced signal transduction in plants. Annu. Rev. Plant Physiol. Plant Mol. Biol. 51: 49-81.

Smeekens, S. and F. Rook. 1997. Sugar sensing and sugar-mediated signal transduction in plants. Plant Physiol. 115:7-13.

Sonnewald, U., M.R. Hajirezaei, J. Kossmann, A. Heyer, R.N. Trethewey, and L. Willmitzer. 1997. Increased potato tuber size resulting from apoplastic expression of a yeast invertase. Nature Biotechnol. 15:794797.

Sonnewald, U., J. Lerchil, R. Zrenner, and W. Frommer. 1994. Manipulation of sink-source relations in transgenic plants. Plant Cell Environ. 17:649-658.

Sonnewald, U., M. Brauer, A. von Schaewen, M. Stitt, and L. Willmitzer. 1991. Transgenic tobacco plants expressing yeast-derived invertase in either the cytosol, vacuole or apoplast: a powerful tool for studying sucrose metabolism and sink/source interactions. Plant J. 1:95-106.

Stitt, M. and A. Krapp. 1999. The interaction between elevated carbon dioxide and nitrogen nutrition: The physiological and molecular background. Plant Cell Environ. 22:583-621.

Stitt, M. and U. Sonnewald. 1995. Regulation of metabolism in transgenic plants. Annu. Rev. Plant Physiol. Plant Mol. Biol. 46:341-368.

Stitt, M., A. von Schaewan, and L. Willmitzer. 1990. "Sink" regulation of photosynthetic metabolism in transgenic tobacco plants expressing yeast invertase in their cell wall involves a decrease of the Calvin-cycle enzymes and an increase of glycolytic enzymes. Planta 183:40-50.

Sturm, A. and G-Q. Tang. 1999. The sucrose-cleaving enzymes of plants are crucial for development, growth and carbon partitioning. Trends Plant Sci. 4:401-407.

Sturm, A., V. Sebkova, K. Lorenz, M. Hardegger, S. Lienhard, and C. Unger. 1995. Development- and organ-specific expression of the genes for sucrose synthase and three isoenzymes of acid $\alpha$-fructofuranosidase in carrot. Planta 195:601-610.

Sweetlove, L.J., J Kossmann, J.W. Riesmeier, R. Trethewey, and S.A. Hill. 1998. The control of source to sink carbon flux during tuber development in potato. Plant J. 15:697-706.

Talercio, E.W., J.Y. Kim, A. Mahe, S. Shanker, J. Choi, W.H. Chen, J. Prioul, and P.S. Chourey. 1999. Isolation, characterization and expression analysis of two cell wall invertase genes in maize. J. Plant Physiol. 155:197-204 
Tang, G-Q., M. Luscher, and A. Sturm. 1999. Antisense repression of vacuolar and cell wall invertase in transgenic carrot alters early plant development and sucrose partitioning. Plant Cell 11:177-189.

Tang, G-Q. and A. Sturm. 1999. Antisense repression of sucrose synthase in carrot (Daucus carrota L.) Affects growth rather than sucrose partitioning. Plant Mol. Biol. 41:465-479.

TaubergerE., S. Hoffmann-Benning, H. Fleischer-Notter, L. Willmitzer, and J. Fisahn. 1999. Impact of invertase overexpression on cell size, starch granule formation and cell wall properties during tuber development in potatoes with modified carbon allocation patterns. J. Expt. Bot. 50:477-486.

Thomas, B.R. and R.L. Rodriguez. 1994. Metabolite signals regulate gene expression and source-sink relations in creal seedlings. Plant Physiol. 106:1235-1239.

Trethewey, R.N., P. Geigenberger, K. Riedel, M.R. Hajirezaei, U. Sonnewald, M. Stitt, J.W. Riesmeier, and L. Willmitzer. 1998. Combined expression of glucokinase and invertase in potato-tubers leads to a dramatic reduction in starch accumulation and a stimulation of glycolysis. Plant J. 15:109-118.

Trumbly, R.J. 1992. Glucose repression in the yeast Saccharomyces cerevisiae. Mol. Microbiol. 6:15-21.

Tsai, C.H., A. Miller, M. Spalding, and S. Rodermel. 1997. Source strength regulates an early phase transition of tobacco shoot morphogenesis. Plant Physiol. 115:907-914.

Van Oosten, J.J. and R.T. Besford. 1996. Acclimation of photosynthesis to elevated $\mathrm{CO}_{2}$ through feedback regulation of gene expression: Climate of opinion. Photosyn. Res. 48:353-365.

Vaulont, S. and A. Kahn. 1994. Transcriptional control of metabolic regulation genes by carbohydrates. FASEB J. 8:28-35.

von Schaewen, A., M. Stitt, R. Schmidt, U. Sonnewald, and L. Willmitzer. 1990. Expression of a yeast-derived invertase in the cell wall of tobacco and Arabidopsis plants leads to accumulation of carbohydrate and inhibition of photosynthesis and strongly influences growth and phenotype of transgenic tobacco plants. EMBO J. 9:3033-3044.

Walker, R.P., A.L. Winters, and C.J. Pollock. 1997. Purification and characterization of invertases from leaves of Lolium temulentum. New Phytol. 135:259-266.

Walker, R.P. and C.J. Pollock. 1993. The purification and characterization of soluble acid invertase from coleoptiles of wheat (Triticum aestivum L. cv. Avalon). J. Expt. Bot. 44:1029-1037.

Wang, R, K. Gruegler, S.T. LaBrie, and N.M. Crawford. 2000. Genomic analysis of a nutrient response in Arabidopsis reveals diverse expression patterns and novel metabolic and potential regulatory genes induced by nitrate. Plant Cell. 12:1491-1509.

Weber, H., L. Borisjuk, and U. Wobus. 1996. Controlling seed development and seed size in Vicia faba: A role for seed coat-associated invertases and carbohydrate state. Plant J. 10:823-834.

Weber, H., L. Borisjuk, U. Heim, P. Buchner, and U. Wobus. 1995. Seed coat-associated invertases of fava bean control both unloading and storage functions: cloning of cDNAs and cell type-specific expression. Plant Cell 7:1835-1846.

Weber, H., U. Heim, S Golombek, L Borisjuk, R. Manteuffel, and U. Wobus. 1998. Expression of a yeast-derived invertase in developing cotyledons of Vicia narbonensis alters the carbohydrate state and affects storage functions. Plant J. 16:163-172.

Weber, H. and U. Wobus. 1997. Sugar import and metabolism during seed development. Trends Plant Sci. 2:169-174.

Winter, H., J. Huber, and S.C. Huber. 1998. Identification of sucrose synthase as an actin-binding protein. FEBS Lett. 430:205-208.

Wittich, P.E. and D. Vreugenhil. 1998. Localization of sucrose synthase activity in developing maize kernels by insitu enzyme histochemistry. J. Expt. Bot. 49:1163-1171.

Xu, J., W.T. Avigne, D.R. McCarty, and K.E. Koch. 1996. A similar dichotomy of sugar modulation and developmental expression affects both paths of sucrose metabolism: evidence from a maize invertase gene family. Plant Cell 8:1209-1220.

Zeng, Y., Y. Wu, W.T. Avigne, and K.E. Koch. 1998. Differential regulation of sugar-sensitive sucrose syntheses by hypoxia and anoxia indicate complementary transcriptional and post-transcriptional responses. Plant Physiol. 116:1573-1583.

Zeng, Y., Y.Wu, W. Avigne, and K. Koch. 1999. Rapid repression of maize invertases by low oxygen. Invertase/sucrose synthase balance, sugar signaling potential, and seeding survival. Plant Physiol. 121:599-608.

Zhang, X.Q. and R. Chollet. 1997. Seryl-phosphorylation of soybean nodule sucrose synthase (nodulin-100) by a $\mathrm{Ca}^{+2}$-dependent protein kinase. FEBS Lett. 410:126-130.

Zimmerman, M.H. and H. Ziegler. 1975. List of sugars and sugar alcohols in sieve-tube exudates, p. 480-503. In: M.H. Zimmerman and J.A. Milburn (eds.). Transport in plants I: Phloem transport. SpringerVerlag, New York.

Zrenner, R., K. Schuler, and U. Sonnewald. 1996. Soluble acid invertase determines the hexose-to-sucrose ratio in cold stored potato tubers. Planta 198:246-252.

Zrenner, R., M. Salanoubat, L. Willmitzer, and U. Sonnewald. 1995. Evidence of the crucial role of sucrose synthase for sink strength using transgenic potato plants (Solanum tuberosum L.). Plant J. 7:97-107. 